\title{
Predictors of low self-rated health in patients aged 65+ after total hip-replacement (THR) - A cross-sectional study
}

\author{
Britta Hordam ${ }^{1}$, Lars Hemmingsen ${ }^{2}$ \\ 1. Research Unit, University College Sealand, Denmark. 2. Research Unit, Hospital of Naestved, Denmark.
}

Correspondence: Britta Hordam. Address: University College Sealand, Research Unit. Slagelsevej 7, 4180 Soro, Denmark. Telephone: 457-248-1275. Email: bho@ucsj.dk.

Received: May 29, 2012

Accepted: August 9, 2012

DOI : $10.5430 /$ jnep.v3n2p86

URL: http://dx.doi.org/10.5430/jnep.v3n2p86

\section{Abstract}

Background: THR is as a very efficient operation in terms of pain-relief and improvement of walking ability. However, after the operation some patients still report low health status.

Aim: The aim of the study is to describe health status among the patients following THR and to identify factors predicting low self-rated health after surgery.

Material and method: A cross-sectional study including 287 patients aged 65+, who had had THR within 12-months were performed. Patients from five Danish counties received a mailed questionnaire assessing health status and demographic data. Short Form-36 measures eight domains of importance for health status. The measures are physical function, role physical, bodily pain, social function, role emotional, general health, vitality and mental health.

Results: Patients living alone or being depend on help from others had a significantly increased risk of having lower scores in 7 of 8 domains of health status after surgery. Regression analysis revealed that living alone could predict significant lower score on two of the eight health domains.

Conclusions: Our results indicate that health status is scored low in patients living alone or having no support. This implies that there might be a need for further postoperative interventions.

\section{Key words}

THR/THA, Nursing, Elderly, Rehabilitation, SF-36

\section{I ntroduction}

Osteoarthrosis is the most frequent disease among people over 65 years. Men and women with osteoarthrosis have a life-expectancy as the normal population, but their quality of life seems to be compromised compared to others in the same age group due to pain, reduced joint movement and walking ability ${ }^{[1]}$. Total hip replacement (THR) is a very effective and one of the most common treatments. The surgical procedures are proven effective in relieving the patients' pain and 
improving their walking ability. As osteoarthrosis affects the middle-aged and elderly, the need of THR is predicted to increase during the next decades due to the higher percentage of elderly in society ${ }^{[2]}$.

For some persons, this type of surgery may not benefit the overall quality of life, as their health status does not improve accordingly. Patients do expect an overall improvement in all functions of their daily life after surgery and not only pain relief and improved walking ability ${ }^{[3-12]}$ but a number of studies have described that patients live the life they did before $\mathrm{THR}^{[4,9,11-13]}$. These studies also indicate that married couples seem to have a better health status compared to both men and women living alone or patients dependent on others help ${ }^{[13,14]}$.

Studies have reported that to regain health status postoperative training during the first six months postoperatively may be of decisive importance for the long- term benefit ${ }^{[3,6-12,15,17,18]}$.

No previous Danish studies have identified health status among patients aged over 65 years after THA and identified whether specific groups of patients are at risk of having a low health status after THA. Thus, before recommending a permanent rehabilitation and intervention program a cross-sectional study estimating the general health status ${ }^{[19-21]}$ was carried out.

Aims of the study were to describe health status of patients with osteoarthrosis aged over 65 years following THR and to identify factors predicting low self-rated health after surgery

\section{Patients and methods}

Patients over 65 years from five different counties in Denmark, who had had a THA within the last twelve months, were invited to participate in the study. As shown in table 1, totally 314 patients from the hospitals catchments areas underwent THR within one year were enrolled, 287 patients (91.4\%) participated in the study. A total of 27 people were non-responders and they were similar to the responders in terms of age and gender.

Table 1. Characteristics of participating patients

\begin{tabular}{llll}
\hline $\mathbf{N}=\mathbf{2 8 7}$ & $\begin{array}{l}\text { Men } \\
\mathbf{n = 1 0 8}\end{array}$ & $\begin{array}{l}\text { Women } \\
\mathbf{n = 1 7 9}\end{array}$ & \\
\hline Age & $72.7(8.1)$ & $73.2(8.6)$ & $p=.678$ \\
Mean(SD) & $65-94$ & $65-87$ & $p=.000$ \\
Range: & $23.4 \%$ & $63.1 \%$ & $p=.001$ \\
Living alone & $81.0 \%$ & $61.3 \%$ & \\
Dependency on help & & & \\
\hline
\end{tabular}

\subsection{Design}

A cross-sectional study design was used. All patients were mailed an introduction letter together with a questionnaire containing a number and a prepaid return envelope. In the questionnaire they were asked to give demographic data and assess their health status and report if they were dependent on help defined as support from family or close relatives. Patients' who had not responded with-in two weeks received a reminder. The questionnaires were returned to the hospitals where the patients had their THR surgery.

\subsection{Health status}

The health status was assessed by Short-Form 36 (SF-36). The SF-36 is a self-administered generic questionnaire that used, reliable, and valid for measuring functioning, well-being and general health status ${ }^{[19]}$. The SF-36 is a much used questionnaire in the western countries for evaluating patients' self-rated health. Besides, it is available in Danish version and previously validated in a sample of the general population ${ }^{[20]}$, therefore Danish norm data are available. Reflecting the 
impact of both dysfunctions and general health perception the questionnaire measures: Physical function (PF), role physical (RF), bodily pain (BP), social function (SF) role emotional (RE), general health (GH), vitality (VT) and mental health $(\mathrm{MH}){ }^{[22]}$. The questions related to each dimension are scored on a scale from 0 (worst score) to 100 (best score). In the present study the scoring of data was done according to the Danish manual to SF-36 manual ${ }^{[19]}$.

\subsection{Ethics}

The study was approved by The Local Research Ethics Committee and reported to The Data Protection Authorities. Written information was given to all participants and it was made clear that participation was voluntary.

\subsection{Data analysis}

Data were processed by means of the statistics program Statistical Package for Social Sciences (SPSS). The results using continuous data are given as mean (+/-1SD). If data were normally distributed the Student's unpaired two-tailed t-test was used. To test for significance between nominal or ordinal-level data, the chi-square test was used. To estimate risks and to test for associations Odd Ratios (OR) with a confidence interval at $95 \%$ were calculated. $P$-values below 0.05 were considered significant.

\section{Results}

In this cross-sectional study patients of the age of 65-95 were enrolled from hospitals in five different counties in Denmark. $63 \%$ of the women and $23 \%$ of the men were living alone. The characteristics of the participating patients are given in Table 1.

\subsection{Physical dysfunction}

Table 2 shows the scores from men and women divided in two age groups (65-74 and 75+). In 6 out of 8 domains women age +75 scores significant lower compared with women age 65-74.

Table 2. Mean score of self-rated health in two age groups stratified by gender

\begin{tabular}{|c|c|c|c|c|c|c|}
\hline & \multicolumn{3}{|l|}{ Men } & \multicolumn{3}{|l|}{ Women } \\
\hline & Age : $65-74(n=63)$ & $+75(n=42)$ & $p$ & Age : $65-74(n=91)$ & $+75(n=86)$ & $p$ \\
\hline \multicolumn{7}{|l|}{ Dysfunction } \\
\hline $\begin{array}{l}\text { Physical functioning } \\
\text { (PF) }\end{array}$ & $55.3(27.4)$ & $52.4(25.5)$ & .584 & $51.9(25.4)$ & $40.6(24.6)$ & .003 \\
\hline Role physical (RP) & 26.3(39.0) & $31.0(40.1)$ & .564 & $38.9(42.9)$ & 18.2(33.6) & .001 \\
\hline Bodily pain (BP) & $60.5(30.1)$ & 63.1(29.5) & .663 & $61.2(27.0)$ & $51.0(26.9)$ & .014 \\
\hline $\begin{array}{l}\text { Social functioning } \\
\text { (SF) }\end{array}$ & $79.9(25.0)$ & $86.0(21.3)$ & .200 & 78.6(28.6) & 72.2(29.3) & .150 \\
\hline Role emotional (RE) & $50.9(39.1)$ & $44.1(44.5)$ & .441 & $54.3(44.6)$ & $35.0(40.1)$ & .006 \\
\hline \multicolumn{7}{|l|}{ General Health } \\
\hline General health(GH) & $62.0(22.1)$ & $64.8(19.9)$ & .530 & $61.5(23.2)$ & $56.9(20.6)$ & .181 \\
\hline Vitality (VT) & $58.6(29.5)$ & $62.5(24.7)$ & .495 & $60.1(26.0)$ & $50.0(26.4)$ & .014 \\
\hline Mental health (ME) & $77.3(23.4)$ & 79.8(19.8) & .580 & $75.8(21.6)$ & $67.8(23.5)$ & .024 \\
\hline
\end{tabular}

Overall women had a significantly lower RP and SF score than men. In the older age group women living alone had a lower RP score $(P=.018)$ and SF score $(P=.037)$ than women living with another person. Women had a significantly lower score in four subscales within the domain of dysfunction, when they were dependent on others` help: $\mathrm{PF}(P=.006)$, $\mathrm{RP}(P=.000)$, SF $(P=.005)$ and RE $(P=.016)$.No differences were found with regards to physical dysfunction and age for men. Women aged $75+$ scored significantly lower than men $75+$ in four out of five domains within dysfunction, $\mathrm{PF}(P=$ $.010)$, BP $(P=.015)$, SF $(P=.008)$ and RE $(P=.007)$. 


\subsection{Risk factors}

To establish the risk factors for dysfunction and general health perception ORs were calculated comparing women with men, age 75+ years with 65-74 years, living alone or living with someone and not having support from others/family with having support. The risk was calculated in relation to having an equal/higher or lower score than the mean of the total population within the respective domain. In Table 3 the ORs are presented.

Table 3. Odd ratios for having a score of self-rated health above the population's mean

\begin{tabular}{lllll}
\hline & Women vs. men & Age 75+vs. age 65-74 & $\begin{array}{l}\text { Living alone vs. living } \\
\text { with someone }\end{array}$ & $\begin{array}{l}\text { No support vs. having } \\
\text { support }\end{array}$ \\
\hline & OR (CI95\%) & OR (CI95\%) & OR (CI95\%) & OR (CI95\%) \\
Dysfunction: & & & & $1.54(0.92-2.56)$ \\
Physical functioning (PF) & $1.62(0.99-2.64)$ & $1.53(0.96-2.47)$ & $1.62(1.01-2.60)^{*}$ & $2.32(1.30-4.12)^{*}$ \\
Role physical (RP) & $1.10(0.67-1.82)$ & $1.72(1.04-2.85)$ & $1.70(1.04-2.80)^{*}$ & $1.70(1.02-2.85)^{*}$ \\
Bodily pain (BP) & $1.38(0.85-2.24)$ & $1.30(0.81-2.10)$ & $1.61(1.00-2.60)^{*}$ & $2.05(1.22-3.43)^{*}$ \\
Social functioning (SF) & $1.21(0.74-1.97)$ & $1.22(0.76-1.98)$ & $1.69(1.05-2.74)^{*}$ & $2.20(1.25-3.89)^{*}$ \\
Role emotional (RE) & $1.02(0.61-1.70)$ & $1.59(0.96-2.64)$ & $1.53(0.92-2.52)$ & \\
General Health: & & & & $2.53(1.55-4.12)^{*}$ \\
General health (GH) & $1.77(1.08-2.91)^{*}$ & $1.14(0.71-1.85)$ & $1.69(1.04-2.73)^{*}$ & $1.71(1.02-2.88)^{*}$ \\
Vitality (VT) & $1.49(0.91-2.43)$ & $1.19(0.74-1.93)$ & $2.09(1.28-3.42)^{*}$ & $2.40(1.41-4.08)^{*}$ \\
Mental health (ME) & $1.92(1.16-3.18)^{*}$ & $1.64(1.01-2.66)$ & & \\
\hline
\end{tabular}

* Significant increased risk.

Living alone or having no support from family members was associated with a significant higher risk within seven out of eight domains, but is this finding due to the fact, that we only have looked at one variable at a time in the analysis. Therefore, a multiple linear regression analysis was performed. We did this in order to be able to predict factors of importance for a low score after hip surgery.

We wanted to compare the significance of preoperative status of patients in relation to gender, age, living alone and the need for help with the postoperative scoring on each of the eight domains. We used the same dichotomous variables as in table 3. Living alone was the only variable predicting a lower score postoperatively within general health perception (GH) and Mental Health Scale (MH). The likelihood of a low score after surgery are more than $95 \%$ if you preoperatively are living alone, beta -018$)$ for $\mathrm{GH}(P=.038)$ and beta -0.7 for $\mathrm{MH}(P=.018)$. We found no other significant predictions.

\section{Discussion}

The present study showed that patients' risk of a low score in health status measured by the SF-36 was significantly increased if the patients were living alone or had no support from family/others.

Older women (75+) had significantly lower health status than women (65-74).Women aged 75+ had generally the lowest score of health status.

In Denmark, males account for about $40 \%$ of THR patients. In this study they accounted for 38\% (CI: 95\%: 32-44), which makes the study population representative of gender. Hip-replacement surgery was performed in 52 hospitals in Denmark during the study period. The present study enjoys good extern validity as the hospitals were randomly chosen and no hospital refused to participate. Hence 5(9.6\%) of the 52 Danish hospitals performing hip-replacement surgery participated in the study, covering $6.3 \%$ of all hip-replacement surgery performed within in the study period ${ }^{[2]}$.

A validity study has confirmed the internal consistency and homogeneity of the Danish version of the SF-36 ${ }^{[19]}$, which is an established instrument for assessment of longitudinal changes in health status ${ }^{[22]}$ also applicable in total hip-replacement contexts ${ }^{[3-12]}$. In a Danish study of data quality, the SF-36 could discriminate between levels of health in 
all subgroups but there were skewness, kurtosis and ceiling effects in many subgroups except for elderly people and people suffering from chronic diseases ${ }^{[21]}$. Although the SF-36 includes eight distinct health status concepts and one item measuring self-reported health transition, important health concepts are not represented. Among those omitted are: health distress, family functioning, sexual functioning, and cognitive functioning and sleep disorders ${ }^{[22]}$. Adding these concepts would roughly multiply the response burden four-fold ${ }^{[2]}$, and measuring a comprehensive set of health concepts and the full range of levels for each concept does not necessarily bring about greater detail. Short-form measures are likely to have at least two types of problems: 1) ceiling effects which entail a substantial number of people getting the highest possible scores; and 2) floor effects which include a substantial number of people receiving the lowest possible scores in a given population ${ }^{[22]}$. Ceiling and floor effects were demonstrated in the Danish validation study of the SF-36 ${ }^{[20]}$. In the present study, a floor effect was found in the sub-scales RP and RE because 57\% (RP) and 39\% (RE) scored zero on these scales. A ceiling effect was not present as only $4-8 \%$ of patients scored 100 at least on one scale.

Several studies have documented the efficiency of THA in improvement in functions of daily life and pain relief ${ }^{[3-12]}$. Even though a number of studies have described that patients more or less live the life they did before surgery and that they do not adapt to the new possibilities of living ${ }^{[4,9,11-13,23]}$, only three studies have tried to identify predictors of patients that do not improve their health status after THR ${ }^{[12,17,18]}$.

In a five years follow-up study young age, male gender, minimal concomitant diseases, use of epidural anaesthesia, lack of readmission within 30 days, and higher preoperative functional status were positively correlated with health related quality of life ${ }^{[17]}$. Six months after THR older age, presence of contralateral hip osteoarthritis, back pain and preoperatively mental health status predicted the outcome after surgery ${ }^{[18]}$.

To our knowledge no studies have reported predictors for health status after one year.

In several studies women report a higher degree of dysfunctions than men ${ }^{[12,17,18,23-25]}$. However, in these studies women were older and more likely to have concomitant diseases ${ }^{[11,26]}$. In one study the patients were reported to score lower at one month after discharge compared with those in a similar population. Besides, the female patients reported dysfunction according to general health, anxiety, depression, self-esteem and experience of sex life compared with men ${ }^{[11,24,25]}$. In another study the women were less likely than the men to be married, able to perform basic self-care activities and more demanding activities required for independent living, recreation and maintaining a household. Women were also more anxious and reported more symptoms of depressions than men ${ }^{[26]}$. In the present study we found the same patterns in the rating of health status, but the women were not older than the men. No data are available in this study to explain this difference.

Even though women reported more dysfunctions, the multiple regression analysis revealed that the living alone was the only factors that significantly could predict a lower score postoperatively within GH and MH.

\section{Limitations due to the study}

The findings in this study should be interpreted with caution due to the cross-sectional nature of the study. Hence, it only shows the characteristics of the chosen population at the specific time within specific domains. Patients' health status was measured within twelve months after THR using the SF-36 and the findings therefore show, that the patients' activity of daily living and self-care ability was compromised and that a rehabilitation program aimed at improving these dimensions might be needed ${ }^{[12,17,18,23]}$.

However, intervention research is needed before such a program can be implemented. It is necessary to perform further research into specific recommendations for men and women aged over 65 years after THR, considering the individual patients risk factors. 


\section{Conclusion}

Patients` health status after THR could be used as a means to identify dysfunction and as a measure for outcome. These efforts may improve patients` health status and benefit the total outcome of THR surgery. This study indicates that twelve months after surgery patients still had dysfunction

In conclusion the present results demonstrate a need of a structured and specific intervention program focusing on patients` health status both preoperatively and postoperatively. Moreover, a follow-up study should last more than six months and should address improvement in patients` self-rated health measured in terms of activities of daily living and self-care ability.

\section{Clinical assumptions}

It seems that specific groups such as women living alone, patients aged 75+ and patients depended on help from family have an increased risk of having dysfunctions and in need for individual follow-up and advices to improve the health status.

\section{Author contribution}

Britta Hørdam was responsible for the research and her co-author for general supervising.

\section{Funding}

This study has financially been supported by TRYGFONDEN in Denmark.

\section{References}

[1] Croft P., Lewis M., Wynn Jones, C., Coggon D., Cooper C. Health status in patients awaiting hip replacement for osteoarthritis. I: Reumatology. 2002; 41: 1001-7.

[2] Danish Arthroplasty Registry [Internet]. Annual report, 2008. Available from: http: //www.dhr.dk

[3] Jacobsson Sv.A., Rehnberg C., Djerf K. Risks, Benefits and Economic Consequences of Total Hip Arthroplasty in an Aged Population. I: Scand J Soc Med.1991; 19(1): 72-78. PMid:1925432

[4] Mahomad NN., Liang MH., Cook EF., Daltroy LH., Fortin PR., Fossel AH., Katz JN. The importance of patient expectation in predicting functional outcomes after total joint arthroplasty. J Reumatol. Jun. 2002; 29(6): 1273-9. PMid:12064846

[5] Ragab AA., Validity of self-assessment outcome questionnaires: patient-physician discrepancy in outcome interpretation. Bio med Sci Instrum.2003; 39: 579-84. PMid:12724955

[6] Rissanen P., Aro S., Sintonen H., Slãtis P., Paavolainen P. Quality of life and functional ability in hip- and knee replacement: A Prospective Study. I: Quality-Of-Life-Research. Feb.1996; 5(1): 56-64. PMid:8901367 http://dx.doi.org/10.1007/BF00435969

[7] Södermann P., Malchau H., Herberts P. Outcome after total hip arthroplasty. Acta Orthop Scand.2000; 71(4): 354-9. PMid:11028882

[8] Wiklund I. A. Comparison of Quality of Life before and After Arthroplasty in Patients Who Had Arthrosis of the Hip Joint. The Journal of Bone and Joint Surgery.1991; 73A (5).

[9] Ostendorf M., Malchau H. Patient-reported outcome in total hip replacement. I: The Journal of Bone\& Joint Surgery. 2004; 86-B (6).

[10] Cushanagan J., Coggon D., Reading I., Croft P., Byng P., Cox K., et al. Long-term outcome following total hip arthroplasty: a controlled longitudinal study. I: Arthritis Rheum. 2007; 57: 1375-80. http://dx.doi.org/10.1002/art.23101

[11] Montin L., Leino-Kilpi H., Suominen T., Leipstö J. A systematic review of empirical studies between 1996-2005 of patient outcomes of total hip arthroplasty and related factors. I: Journal of Clinical Nursing. 2008; 17: 40-45. PMid:18088258 http://dx.doi.org/10.1111/j.1365-2702.2007.01944.x

[12] Gandhi R., Dhotar H., Davey R., Mahomad NN. Predicting the Long-term Outcomes of Total Hip Replacement. I: The Journal of Rheumatology. 2010; 37: 12. http://dx.doi.org/103899/jrheum.100149.

[13] Lyndell J., Brodie Rodney M. Changes in Health Status and Elderly Patients Following Total Hip Replacement Surgery, Gerontological Nursing. 1998; 23(3).

[14] Smith C. Total Hip Replacement. I: Nursing Times.1989; 85(46). 
[15] Holmberg Sv.1992. Life Expectancy after Total Hip Arthroplasty. The Journal of Arthroplasty.1992; 7(2):183-187. http://dx.doi.org/10.1016/0883-5403(92)90014-H

[16] Lieberman JR., Dorey F., Shekelle P., Schumacher L., Kilgus DJ., Thomas BJ., Finermann GA. Outcome after total hip artroplasty. Comparison of a traditional Disease-specific and a quality-of-life measurement I: Journal of Artroplasty. Sep.1997; 12 (6): $639-45$. http://dx.doi.org/10.1016/S0883-5403(97)90136-4

[17] Hon-Yi Shi., Khan M., Culbertsen R., Chang JK., Wang JW., Chiu HC., Health-related quality of life after total hip replacement: a Taiwan study, I: International Orthopaedics. 2009; 33:1217-1222. PMid:18974987

[18] Quintana J., Escobar A., Aguirre U., Lafuente I., Arenaza JC. Predictors of Health-related Quality-of-life Change after Total Hip Arthroplasty. I: Clin orthop Relat Res. 2009; 467(11): 2886-2894. PMid:19412646 http://dx.doi.org/10.1007/s11999-009-0868-9

[19] Bjorner J., Kristensen TS., Orth-Gomer K., Tibblin G., Sullivan M., Westerholm P. Self-Rated Health, a useful concept in research, prevention and clinical medicine. Swedish Council for Planning Of Research (Uppsala, Sverige). 1996.

[20] Bjorner J., Damgaard M., Watt T., Bech P., Kristensen T., Modvig J., Thuneborg K. Dansk Manual til SF-36, Lif København/Copenhagen. 1997.

[21] Bjorner JB., Thunedborg K., Kristensen TS., Modvig J., Bech P., The Danish SF-36 Health Survey: Translation and Preliminary Validity Studies. J Clin Epidemiol.1998; 51(11): 991-9. http://dx.doi.org/10.1016/S0895-4356(98)00091-2

[22] Ware JE., Sherbourne CD. The MOS 36-item short-form health survey (SF-36). Medical Care. 1992; 30(6): 473-83. PMid:1593914 http://dx.doi.org/10.1097/00005650-199206000-00002

[23] Hordam B., Pedersen P.U., Sabroe S., Soballe K. Rehabilitation of patients aged 65 and over after total hip replacement-Based on patients' health status. Faculty of Health Sciences. University of Aarhus, Denmark. 2008.

[24] Vaccarino V., Lin ZQ., Kasl SV., Mattera JA., Abrahamson JL., Krumholz HM. Gender differences in recovery after coronary artery bypass surgery. I: Journal of American Collegium of Cardiology. 2003; 41: 307-14. http://dx.doi.org/10.1016/S0735-1097(02)02698-0

[25] Westin L., Carlsson R., Erhardt L., Cantor-Graae E., McNeil T. Differences in quality of life in men and women with ischemic heart disease. I: Scand Cardiovasc J. 1999; 33: 160-5. http://dx.doi.org/10.1080/14017439950141795

[26] Czajkowski S., Terrin M., Linquist R., Hoogwerf B., Dupuis G., Shumaker SA., Gray JR., Herd JA., Tret-Jacobson D., Zyzanski S., Knatterud GL. Comparison of postoperative characteristic of men and women undergoing coronary artery bypass grafting (The post coronary artery bypass graft CABG biobehavioral study). I: Am J Cardiol.1997; 79: 1017-24.

http://dx.doi.org/10.1016/S0002-9149 (97)00040-4 